\title{
Data Loss Risk: A Multivariate Statistical Methodology Proposal
}

\author{
Heber José de Moura \\ Universidade de Fortaleza, Brazil \\ Charles Ulises de Montreil Carmona \\ Universidade de Fortaleza, Brazil
}

\begin{abstract}
Given that an adequate prioritization of data losses (DL) events is crucial for risk management in institutions of any nature, the present paper proposes a methodology aimed at hierarchizing the events associated with this type of risk. This proposal incorporates three specifications : parametric independence, objectivity and applicability. To illustrate , a framework was applied to records of DatalossDB, a US risk database. An hierarchy model based on Conjoint Analysis (CA) was developed by associating DL with industry sector, incident source and incident type variables. The flexibility of CA derives from its ability to use metric or non-metric variables, as well as from the lack of rigid rules regarding the relation between the combination of attributes and the preferences. The procedure determined the importance of the attributes involved and allowed the prioritization of risk events, which will certainly be useful in guiding the actions towards minimizing the problem.
\end{abstract}

\section{INTRODUCTION}

The modeling and assessment of operational risk (OR) has been given significant scholarly attention. Currently, there is a wide range of qualitative and quantitative methods and instruments aimed at the mitigation of $\mathrm{OR}$, and the development of academic papers on the management and mitigation of OR has been on the rise - probably because of the relevance of the financial industry in the global context. For instance, the contributions of researchers such as Cruz (2004), Chernobai, Rachev \& Fabozzi (2007), Bühlmann, Shevchenko \& Wüthrich (2007), Yasuda (2003) and several others should be cited. However, there is still an issue of concern to institutions and researchers: how to objectively prioritize the processes to be modeled, since they generally constitute a reasonable volume in the company and have different patterns of behavior?

Such an issue becomes even more relevant when we consider that the financial resources directed towards the mitigation of OR are generally limited and large. This aspect makes it even more complex to address this type of risk, which, according to Jobst (2007), cannot be considered a "mere segment of other risks", but one that tends to have its "own life".

Reducing corporate risks generally requires the execution of a series of wide-reaching activities aimed at changing processes which are subject to uncertainty. These activities involve internal and external aspects of companies. Thus, given the diversity and complexity of such monitoring, it is necessary to know in detail the source and development of operational risk events (McClave, 1990) and to establish priorities to address them, particularly because of the considerable impact they have on corporate efficiency.

Given that an adequate prioritization of OR events is crucial for risk management in institutions of any nature, the present paper proposes a methodology aimed at hierarchizing the events associated with this type of risk in order to objectively guide those who are 
responsible for mitigating or even eliminating threats related to the operational processes of the institution.

The method described herein proposes the incorporation of three specifications:

Parametric Independence - As OR encompasses events in the most diverse types originating from several different areas, it is assumed that in most cases it is impossible to model the events through the usual parametric statistical distributions. Therefore, the present proposal is based on the application of nonparametric methods, which allow a greater practical comprehensiveness.

Objectivity - It is necessary to have a formal system for the treatment of OR events. This will prevent the events from being exclusively based on preconceptions about the subject. Nevertheless, the model should allow the integration of data supported by quantitative and subjective metrics, as in the studies by Giudici (2004), Okunev (2005) and Borges \& Moura (2010).

Applicability - The methodology should be suitable for different types of sectors, such as industry, governments, medical services, education, and others. In fact, the applicability of the proposal will be proven later on based on the use of a database of real events occurring in different types of sectors.

To illustrate the construction of a framework, a US open database called DataLossDB (OSF, 2014), which has been extensively used by educational, governmental and commercial entities (Gabbay, 2010), was used. This is a free access data structure originated from a research project sponsored by US private entities to document data loss incidents that are reported voluntarily by institutions around the world. The source gathers information about events involving the loss, theft or disclosure of individual and corporate information.

Finally, the need to prioritize risk events is justified by the large investments made by institutions to reduce and control OR. This is particularly true for the public sector and for larger organizations which deal with significant amounts of information and are hence subject to a wide range of threats. The hierarchical methodology proposed in the present study is applicable to practically any sectors. Therefore, it is expected that it will contribute to the planning of activities aimed at mitigating operational risk in general.

\section{METHOD}

The framework developed was applied to records of Data Loss (DL) events reported to DatalossDB. Each record refers to a company and contains the following variables: Industry sector, Date of the incident, Incident source, Country and Incident Description, Quantity of information items affected by the incident, Financial, Type of information items affected and Breach type.

From 2013 to July 2014, 1982 data loss cases were reported to DatalossDB, including companies that did not report financial losses and those located in other countries. The sample used in the present study included only the cases in which these losses were reported since such information is relevant to the application of the methodology. In addition, cases reported from countries other than the United States were excluded because they generated a very pronounced volatility regarding the types, frequencies and amount of losses. Therefore, the sample was reduced to 355 records with full information on cases of data loss in US companies. The hierarchy model was developed by associating DL with the following variables: Industry Sector, Incident Source and Incident Type, as shown in the following figure: 
TYPE

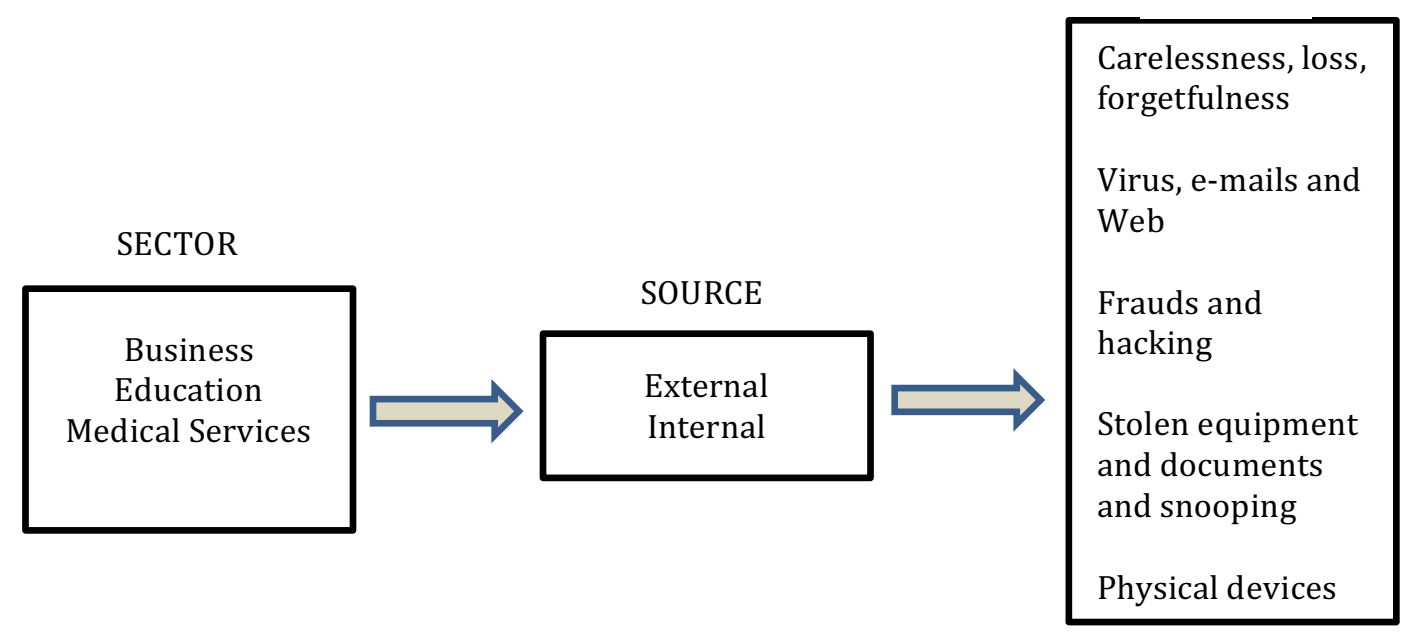

Figure 1. Characterization of DATA LOSS events

An example of an event is the loss of data due to "Frauds and hacking from outside the business sector". So, we can deduce that the grand total of events for this application is 30 ( $3 \times 2 \times 5)$, which corresponds to a combination of the attributes displayed in the figure.

The instrument adopted for the prioritization of events was the Conjoint Analysis (CA), a multivariate dependence technique used to investigate the hierarchy of preferences among alternatives with several attributes (Fávero, 2009). The method is indicated to analyze conjoint effects that two or more qualitative attributes have on the respondent's preference (the dependent variable in the model). One of the advantages of using the CA in the present study is that it allows to understand and monitor the process through which the decision-maker makes his preferences (Hair, 2005).

CA assumes that respondents' preferences are a result of the aggregation of the values of each attribute and can be measured by utilities, which represent the priorities of each combination of attributes (Ribas \& Vieira, 2011). In addition to allowing the hierarchization of events, the technique estimates the relative importance of each attribute and can be applied to each respondent or to the entire sample.

The Conjoint Analysis is suitable for understanding respondents' reactions to various combinations of values associated with each attribute by ranking their preferences , corresponding to dependent variables. The flexibility of the technique derives from its ability to use metric or non-metric dependent variable, as well as from the lack of rigid rules regarding the relation between the combination of attributes and the preferences (Hair, 2005). The CA stands out when compared to other multivariate methods because it allows, first of all, the construction of a set of alternatives combining selected levels of each attribute. Then, the respondent makes his/her choices through the ordinal or interval hierarchization of the alternatives without having to indicate the level of importance of a specific attribute. In fact, the influence of each alternative is generated internally by the CA based on the statistical treatment of all responses, a procedure analogous to discriminant analysis and multiple regression models.

According to the terminology used in CA, the term Factor describes a specific variable, such as Industry Sector, Incident Source, or Incident Type. The values of each of them are called Levels. In Figure 1, the factors were displayed above the rectangles and the levels inside them. 
After the characterization of the event and the determination of the sample, this framework requires an experiment in which a risk management specialist should be requested to classify the thirty incidents based on the 6 different criteria listed below. In this phase, the respondent should assign scores from 1 to 100 . Higher scores indicate high-risk incidents which require greater attention and priority for their mitigation. The criteria suggested are:

Frequency - the number of times each event took place within a period. It is based on the quantity and not on the magnitude of losses;

Mean - the mean financial loss caused by a particular event. It is based on the arithmetic mean of losses;

Median - the central financial loss disregarding the extreme values. The median is the central value of a data set. It represents the value that divides the distribution into two equal halves.

Severity - the amount of losses. It is the product of the mean loss and the number of times the event took place.

Cost - the estimated expenditure to reduce the mean loss (or the severity) to the lowest level acceptable by the company;

Effectiveness - the maximum reduction of the mean loss (or severity) achieved by using the maximum number of resources acceptable by the institution.

Since CA allows to generate composite criteria from a few basic ones, it is possible to generate other criteria from the initial six. In the present case, the following criteria are suggested.

\begin{tabular}{ll}
\hline \multicolumn{1}{c}{ Criteria } \\
$\begin{array}{ll}\text { \{Frequency, median, cost } \\
\text { effectiveness }\end{array}$ & $\begin{array}{l}\text { It considers the events and the central losses in addition to the economic } \\
\text { rationality of the investment }\end{array}$ \\
\hline $\begin{array}{l}\text { \{Frequency, severity } \\
\text { Generally adopted by banks, it assumes the independence between frequency } \\
\text { and amount of loss }\end{array}$ \\
\hline $\begin{array}{l}\text { \{Frequency, mean\} } \\
\text { ICost, effectivenes\} }\end{array}$ & It has an economic connotation as it seeks to apply resources more effectively \\
\hline $\begin{array}{l}\text { IFrequency, severity, cost } \\
\text { effectiveness }\end{array}$ & $\begin{array}{l}\text { It takes into account the events and the magnitude of the loss in addition to the } \\
\text { economic rationality of the investment }\end{array}$ \\
\hline
\end{tabular}

Figure 2. Composite criteria for classification generated from the basic criteria.

In this case, the model allows to generate 11 groups with 30 events each, where the first 6 correspond to the basic criteria (hierarchized by the respondent) and the remaining 5 are generated directly in the CA by combining the previous ones.

The model can be applied by using the Conjoint Analysis procedure in SPSS, obtaining the following results:

Utility-generating function coefficients - the inputs used for calculating individual level utilities. Since an additive model is used, the utility calculation is based on the sum of values that make up the event. The generated utilities represent the respondent's preferences in relation to the event formed by the combination of the three attributes already adjusted by the CA procedure. 
Correlation and significance - the measurement of the degree of adjustment of the model based on the correlation between the results generated by it and a validation sample represented by virtual inputs called holdouts. This sample, likewise the one used in discriminant procedures, is not used in the construction of the utility-generating function; it is only used to compare observed values with the estimated equivalents, thus indicating the precision of the adjustment.

\section{RESULTS AND DISCUSSION}

After knowing the set of events, a public sector risk manager was requested to rank the thirty events in order of importance for risk mitigation purposes. The result is summarized in the figure below:

\begin{tabular}{|l|l|r|r|r|r|r|r|r|}
\hline Order & $\begin{array}{l}\text { Basic } \\
\text { Criterion }\end{array}$ & Event1 & Event2 & Event3 & Event4 & Event5 & $\cdots$ & Event30 \\
\hline 1 & Frequency & 2 & 1 & 2 & 49 & 5 & $\cdots$ & 9 \\
\hline 2 & Mean & 1 & 1 & 1 & 4 & 1 & $\cdots$ & 2 \\
\hline 3 & Median & 8 & 3 & 12 & 33 & 31 & $\cdots$ & 39 \\
\hline 4 & Severity & 1 & 1 & 1 & 3 & 1 & $\cdots$ & 1 \\
\hline 5 & Cost & 97 & 95 & 98 & 50 & 99 & $\cdots$ & 88 \\
\hline 6 & Effectiveness & 100 & 100 & 97 & 35 & 97 & $\cdots$ & 70 \\
\hline
\end{tabular}

Figure 3. Classification scores assigned by the respondent according to basic criteria

The description of the events, shown in the first line of the figure 3 , followed the order generated automatically by the CA procedure in SPSS 19.0, where "holdouts" were generated to check on the validity of estimated utilities. In the first line (Frequency), for example, the respondent assigned low importance to the first 3 events and a higher score (49) to event number 4. Regarding the cost and effectiveness of the investments, the respondent assigned major importance to the first 2 events and minor importance to number 4 .

The utilities and other measures estimated for the basic criteria are shown in the following table. 
Table 1. CA results obtained from basic criteria

\begin{tabular}{|c|c|c|c|c|c|c|c|}
\hline Variable & Value & $\begin{array}{l}\text { Frequency } \\
\text { (1) }\end{array}$ & $\begin{array}{l}\text { Mean } \\
\text { (2) }\end{array}$ & $\begin{array}{l}\text { Median } \\
\text { (3) }\end{array}$ & $\begin{array}{l}\text { Severity } \\
\text { (4) }\end{array}$ & Cost (5) & $\begin{array}{l}\text { Effectiveness } \\
\text { (6) }\end{array}$ \\
\hline \multicolumn{8}{|c|}{ Utility-generating function coefficients } \\
\hline \multirow[t]{3}{*}{ Sector } & Business & 4.167 & 6.567 & -5.267 & 6.500 & -4.367 & -2.167 \\
\hline & Education & -3.633 & -3.333 & -4.267 & -3.300 & 3.633 & 4.733 \\
\hline & Medical services & -.533 & -3.233 & 9.533 & -3.200 & .733 & -2.567 \\
\hline \multirow[t]{2}{*}{ Source } & External & 4.300 & 3.533 & 1.967 & 3.400 & -4.133 & -2.267 \\
\hline & Internal & -4.300 & -3.533 & -1.967 & -3.400 & 4.133 & 2.267 \\
\hline \multirow[t]{5}{*}{ Type } & Carelessnes & -7.700 & -3.567 & 1.467 & -3.400 & 8.333 & 11.733 \\
\hline & Virus... & -3.867 & -3.233 & 16.133 & -3.400 & 3.667 & -3.433 \\
\hline & Frauds ... & 15.300 & 13.433 & -5.367 & 13.267 & -16.000 & -20.600 \\
\hline & Stolen equipment ... & 5.467 & -2.900 & -6.867 & -3.067 & -5.833 & -6.933 \\
\hline & Use of physical devices ... & -9.200 & -3.733 & -5.367 & -3.400 & 9.833 & 19.233 \\
\hline \multicolumn{2}{|l|}{ Constant } & 12.033 & 4.733 & 29.367 & 4.400 & 87.667 & 79.267 \\
\hline \multicolumn{8}{|c|}{ ignificance } \\
\hline \multicolumn{2}{|c|}{ Kendall's tau coefficient for "holdouts" } & 0.600 & 0.837 & 0.800 & 0.667 & 0.400 & 0.447 \\
\hline \multicolumn{2}{|c|}{ Significance } & 0.071 & 0.026 & 0.025 & 0.073 & 0.164 & 0.148 \\
\hline \multicolumn{8}{|c|}{ (c) } \\
\hline \multicolumn{2}{|l|}{ Sector } & 19.071 & 29.004 & 35.463 & 29.459 & 19.002 & 14.129 \\
\hline \multicolumn{2}{|l|}{ Source } & 21.027 & 20.703 & 9.425 & 20.441 & 19.636 & 8.774 \\
\hline \multicolumn{2}{|l|}{ Type } & 59.902 & 50.293 & 55.112 & 50.100 & 61.362 & 77.097 \\
\hline
\end{tabular}

The resulting utilities are based on the values that make up the event. Considering, for example, the "Frequency" criterion, the utility of the "Business-Outside-Fraud..." event is calculated as $4.167+4.300+15.300+12.033$, resulting in 35.8 , which corresponds to the priority assigned by the decision maker to that particular event. The utilities of the other events are calculated the same way. It is possible to know the importance that the attribute (level) has for the user: the higher the score, the greater the importance of the attribute. Still about the "Frequency" criterion, it is observed that the incident type "Fraud..." was the most important, with a score of 15.3. It is also possible to know the importance of each factor associated with DL events. Part (c) shows that the Incident type (with weight 59.9) was the indicator that best served to guide the user's choices.

The next table was generated by the CA procedure and describes the utilities and coefficients based on composite criteria. 
Table 2. CA results obtained from composite criteria

\begin{tabular}{|c|c|c|c|c|c|c|c|}
\hline Variable & Value & $\{1,3,5,6\}$ & $\{1,4\}$ & $\{1,2\}$ & $\{5,6\}$ & $\{1,4,5,6\}$ & $\{1,2,5,6\}$ \\
\hline & (a) & lity-genera & ng funct & on coeffi & ients & & \\
\hline Sector & Business & -1.908 & 5.333 & 5.367 & -3.267 & 1.033 & 1.050 \\
\hline & Education & .117 & -3.467 & -3.483 & 4.183 & .358 & .350 \\
\hline & Medical services & 1.792 & -1.867 & -1.883 & -.917 & -1.392 & -1.400 \\
\hline Source & External & -.033 & 3.850 & 3.917 & -3.200 & .325 & .358 \\
\hline & Internal & .033 & -3.850 & -3.917 & 3.200 & -.325 & -.358 \\
\hline Type & Carelessness... & 3.458 & -5.550 & -5.633 & 10.033 & 2.242 & 2.200 \\
\hline & Virus... & 3.125 & -3.633 & -3.550 & .117 & -1.758 & -1.717 \\
\hline & Frauds ... & -6.667 & 14.283 & 14.367 & -18.300 & -2.008 & -1.967 \\
\hline & Stolen equipment ... & -3.542 & 1.200 & 1.283 & -6.383 & -2.592 & -2.550 \\
\hline & Use of physical devices ... & 3.625 & -6.300 & -6.467 & 14.533 & 4.117 & 4.033 \\
\hline Constant & & 52.083 & 8.217 & 8.383 & 83.467 & 45.842 & 45.925 \\
\hline & (b) & Correlati & n and si & nificance & & & \\
\hline Kendall's & au coefficient for holdouts & 0.400 & 0.600 & 0.600 & 0.400 & -0.200 & -0.200 \\
\hline Significan & & 0.164 & 0.071 & 0.071 & 0.164 & 0.312 & 0.312 \\
\hline & (c) & Import & nce of at & ributes & & & \\
\hline Sector & & 26.319 & 23.730 & 23.590 & 15.959 & 24.787 & 25.128 \\
\hline Source & & .474 & 20.764 & 20.880 & 13.709 & 6.644 & 7.350 \\
\hline Type & & 73.207 & 55.506 & 55.531 & 70.332 & 68.569 & 67.521 \\
\hline
\end{tabular}

Considering the number of the basic criteria, the representation $\{1,3,5,6\}$, for example, corresponds to the criterion composed simultaneously of Frequency, Mean, Cost and Effectiveness. The other representations follow the same logic.

The results also show the measurement of the degree of adjustment of the model by calculating the correlation between the generated results and the validation sample, which is represented by the "holdouts". This sample, likewise in discriminant analysis procedures, was not used to build the model, but to indicate the accuracy of the adjustment.

With regard to the basic criteria, it was observed that, apart from "Cost" and "Effectiveness", all the other criteria presented correlations above $60 \%$ and significance below $10 \%$. As for the composite criteria presented in Table 2, the correlations and significance fell short of those associated with the basic criteria.

This may be explained by the fact that composite criteria are generated by a greater number of simultaneous perceptions, which makes it difficult to form a single function that suits the logic resulting from these choices and gives rise to inconsistencies which are difficult to be understood by the model. Naturally, the use of a single basic criterion leads the user to make his/her choices with the least degree of inconsistency.

However, the inconsistencies resulting from the choices are already foreseen by most of the methods that deal with the understanding of this type of information, such as the Analytic Hierarchy Process (AHP) (Goodwin \& Wright, 2004), which even calculates an inconsistency indicator for respondents' choices.

The following table presents a summary of the prioritized events considering some of the criteria adopted. 
Table 3 . Hierarchization of risk events in the first 5 positions according to all classification criteria

\begin{tabular}{|c|c|c|}
\hline \multirow[t]{2}{*}{ Classification } & Risk event & \multirow[t]{2}{*}{ Utility } \\
\hline & Frequency criterion & \\
\hline $1^{\text {st }}$ & External Frauds in the Business sector & 35.8 \\
\hline $2^{\text {nd }}$ & External Frauds in the Medical Services sector & 31.1 \\
\hline $3^{\text {rd }}$ & External Frauds in the Education sector & 28.0 \\
\hline $4^{\text {th }}$ & Fraudes Internas no setor de Negócios & 27.2 \\
\hline $5^{\text {th }}$ & External Thefts in the Business sector & 26.0 \\
\hline \multicolumn{3}{|c|}{ (b) Mean Loss criterion } \\
\hline $1^{\text {st }}$ & External Frauds in the Business sector & 28.3 \\
\hline $2^{\text {nd }}$ & Internal Frauds in the Business sector & 21.2 \\
\hline $3^{\text {rd }}$ & External Frauds in the Medical Services sector & 18.5 \\
\hline $4^{\text {th }}$ & External Frauds in the Education sector & 18.4 \\
\hline $5^{\text {th }}$ & External Thefts in the Business sector & 11.9 \\
\hline \multicolumn{3}{|c|}{$\ldots$} \\
\hline (c) & \multicolumn{2}{|l|}{ Frequency and Median Loss and Cost and Effectiveness criterion } \\
\hline $1^{\text {st }}$ & Other Internal incidentes in the Medical Services sector & 57.53 \\
\hline $2^{\text {nd }}$ & Other External incidentes in the Medical Services sector & 57.47 \\
\hline $3^{\text {rd }}$ & Internal Carelessness in the Medical Services sector & 57.37 \\
\hline $4^{\text {th }}$ & External Carelessness in the Medical Services sector & 57.30 \\
\hline $5^{\text {th }}$ & Internal Access via Web in the Medical Services sector & 57.03 \\
\hline
\end{tabular}

This last table shows the hierarchization of the events obtained by the application of CA and represents the final result made possible by the proposed methodology, which was the objective of present study.

\section{CONCLUSION}

The feasibility of the proposal was confirmed by the use of the DatalossDB database, which allowed the grouping of records on data breaches by different industry sectors, types of information breached, financial losses and other variables taken into account.

In the Conjoint Analysis, the decision-maker was requested to classify, in an ordinal ranking, the previously formatted risk events. After that, the procedure determined the importance of the attributes involved and allowed the prioritization of risk events using multiple criteria, which was the purpose of the study.

Another relevant aspect is the possibility of quantifying the importance that levels and factors related to data breaches have for those in charge of risk management, which will certainly be useful in guiding their actions towards minimizing the problem.

Finally, it is worth noting that although data loss has been used as inspiration for the development of the proposed model, this framework can be adapted to other risk events for which there is interest in prioritizing.

\section{References}

Borges, J., F., Moura, H.J,.(2010) Integração entre abordagens qualitativa e quantitativa para a mitigação do risco operacional: estudo no Banco Central do Brasil. Anais do ENANPAD 2010. Encontro da ANPAD, Rio de Janeiro.

Bühlmann, H., Shevchenko, P., V., Wüthrich, M.,V.,(2007) A "Toy" Model for Operational Risk Quantification using Credibility Theory. The Journal of Operational Risk, v. 2, n. 1, p. 3-20.

Chernobai, A.,S., Rachev, S.,T.,Fabozzi, F.J. (2007) Operational risk : a guide to Basel II capital requirements, models and analysis. New Jersey : John Wiley \& Sons.

Cruz, M . (2004) Operational risk modeling and analysis. London : Incisive financial publishing ltd.

Fávero, L,.P.,Belfiore, P.,Silva, F,.L.,Chan, B.,L.(2009) Análise de dados : modelagem multivariada para tomada de 
decisões. São Paulo, SP: Elsevier

Gabbay, A.,M.(2010) Simulação de Monte Carlo para Mensuração do Risco Operacional: Aplicação do Modelo LDA, Dissertação de mestrado. Universidade Presbiteriana Mackenzie São Paulo.

Giudici, P. (2004) Integration of Qualitative and Quantitative Operational Risk Data: A bayesian approach. In: Cruz, M (editor). Operational Risk Modelling and Analysis: theory and practice. p. 131-138. London: Risk Books.

Goodwin, P., Wright, G.(2004) Decision Analysis for Management Judgment, $3^{\text {rd }}$ ed, London : John Wiley \& Sons Ltd.

Hair Jr, J., Anderson, R., E.,Tatham, R., L., Black, W.,C. (2005) Análise multivariada de dados, 5a edição, Porto Alegre: Artmed.

Jobst, A. ,A. (2007) Consistent Quantitative Operational Risk Measurement and Regulation: challenges of model specification, data collection and loss reporting. IMF Working Paper, November.

McClave, J.,T.,Benson, P.,G. (1990) Statistics for business and economics. Canada: Maxwell Macmillan International Edition.

Okunev, P. (2005). Simple approach to combining internal and external operational loss data in social science research network (Workpaper). Lawrence Berkeley National Laboratory

OSF Open Security Foundation (2014). DataLossDB [data file]. Retrieved from http://datalossdb.org.

Ribas, J. ,R., Vieira, P., R. ,C.(2011) Análise multivariada com o uso do SPSS, Rio de Janeiro : Ed. Ciência Moderna.

Yasuda, I. (2003) Application of Bayesian Inference to Operational Risk Management. Master of Finance, University of Tsukuba, Japan. 